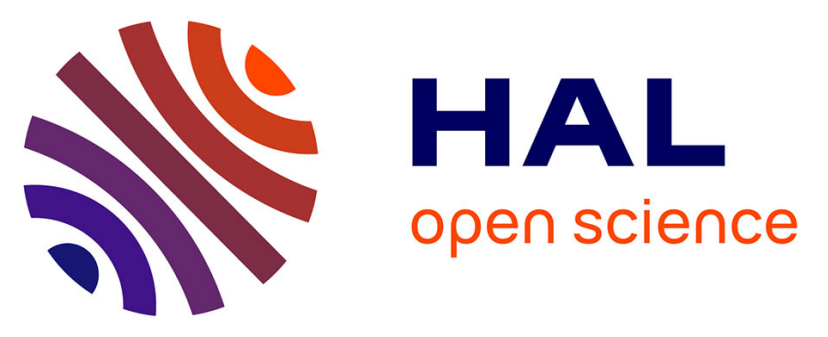

\title{
Proposal to increase the convertible power by an hybrid excitation flux switching synchronous machine associated with an voltage inverter. Application in hybrid or electric vehicle
}

\author{
Emmanuel Hoang, Benjamin Gaussens, Michel Lecrivain, Mohamed Gabsi
}

\section{To cite this version:}

Emmanuel Hoang, Benjamin Gaussens, Michel Lecrivain, Mohamed Gabsi. Proposal to increase the convertible power by an hybrid excitation flux switching synchronous machine associated with an voltage inverter. Application in hybrid or electric vehicle. EVER 2015, Mar 2015, Monaco, Monaco. hal-01138301

\author{
HAL Id: hal-01138301 \\ https://hal.science/hal-01138301
}

Submitted on 1 Apr 2015

HAL is a multi-disciplinary open access archive for the deposit and dissemination of scientific research documents, whether they are published or not. The documents may come from teaching and research institutions in France or abroad, or from public or private research centers.
L'archive ouverte pluridisciplinaire HAL, est destinée au dépôt et à la diffusion de documents scientifiques de niveau recherche, publiés ou non, émanant des établissements d'enseignement et de recherche français ou étrangers, des laboratoires publics ou privés. 


\title{
Proposal to increase the convertible power by an hybrid excitation flux switching synchronous machine associated with an voltage inverter. Application in hybrid or electric vehicle.
}

\author{
Emmanuel HoAnG, Benjamin GAUSSENS, Michel LeCRIVAIN, Mohamed GABSI \\ SATIE-ENS Cachan \\ hoang@satie.ens-cachan.fr
}

\begin{abstract}
Synchronous machines associated with their voltage inverter are generally controlled in current mode. In this paper, we are interested in supplying in full-wave voltage. The second part describes the expected performance with this control mode. In the third part, we present a hybrid excitation flux switching synchronous machine (HEFSSM) whose characteristics make it a potential candidate for electric motors of hybrid or electric vehicles. The experimental results of this HEFSSM containing ferrite permanent magnets $\left(B_{r}=0,4 T\right)$ fed in full-wave voltage to convert the maximal power are presented in the fourth part. In the last section, we present two solutions to increase the maximal convertible power, so the maximal speed in no-load mode.
\end{abstract}

Keywords: hybrid excitation flux switching synchronous machine, voltage control, maximal convertible power.

\section{INTRODUCTION}

With the development of variable speed applications, electrical machine must be able to provide high torque at low speed, with a "' $\cos \varphi$ ' as close as possible to the unit and turn at high speed with minimum losses and with constraints on its cost and its volume. To overcome this problem, the hybrid excitation flux switching synchronous machine (HEFSSM) [1] is interesting because it achieves torque performance comparable to the best permanent magnet synchronous machines and minimizes the iron losses at high speed through its hybrid excitation system.

Like other electrical machines (induction and synchronous), this machine is supply by a conventional voltage inverter at two levels, with six switches. At low speed for torque control, a current control is necessary to minimize losses and torque ripple and maximize the power factor. For higher speeds, a full-wave control voltage maximizes the converted power. This command doesn't require a voltage regulating circuit, there is no PWM control and currents are sinusoidal. They are filtered with the impedance (inductive) of the phases. Note that this command in full-wave voltage minimizes the iron losses [10]. In fact, the absorbed currents create a magnetic armature reaction which takes account of all the harmonic components of voltage.

In Part 2, it is recalled some elements of the theory to understand the voltage control, and we show that this command provides a maximal power conversion. Part 3 describes the HEFSSM with ferrite permanent magnets. Part 4 describes the performance obtained in full-wave voltage. Finally, in Part 5, we present two solutions to increase the converted power, thereby increasing the operating speed range.

\section{ELEMENTS OF THEORY OF VOLT AGE CONTROL}

In a hybrid or electric vehicle, the chain of energy conversion is conventionally constituted by the association of a battery, which is considered in a first approach like a constant voltage source, an electronic power converter and an electric machine (EM). Currently, the majority of EM used in this application is a three-phase machine and electronic power converter is a voltage inverter (VI). The size of this electronic power converter is made aware of the value of the DC bus voltage (storage battery voltage) and knowing, in steady state, the RMS value of the EM currents.

To adapt the EM to the VI, we have a parameter which is the number of turns of the coils constituting the different phases.

The classic control is a current control. This requires the use of current sensors. When the speed increases, the electromotive forces (EMF) created in the machine increase which requires increasing voltages delivered by the VI. At a particular speed, the amplitudes of these voltages are limited due to the value of the DC bus voltage. This particular speed is called conventionally base speed. Beyond this speed, the EM will operate in flux weakening regime [2], [3], [4].

In this operating mode, the RMS values of the voltage provided by the VI are limited by the value of the DC bus voltage:

- $\frac{\mathrm{U}_{\mathrm{DC}}}{2 \sqrt{2}}\left(\approx 0.35 \mathrm{U}_{\mathrm{DC}}\right)$ in PWM mode ;

- $\frac{4}{\pi} \frac{U_{\mathrm{DC}}}{2 \sqrt{2}}\left(\approx 0.45 \mathrm{U}_{\mathrm{DC}}\right)$ in full-wave voltage mode.

In the case of a three-phases SM and assuming that the machine is not saturated and with smooth poles, we can establish the expression of the convertible power:

$$
\mathrm{P}=3 \mathrm{VI} \cos \varphi=3 \mathrm{~V} \frac{\mathrm{E}}{\mathrm{L} \omega} \sin \delta
$$

With $\mathrm{V}$, the RMS value of the phase to neutral voltage, I, the RMS value of the current in a phase, $\varphi$, phase shift between $\underline{\mathrm{V}}$ and I (complex notation), E RMS value of EMF, L, value of cyclic inductance, $\omega$, value of the electrical pulse and $\delta$, angular difference between $\underline{\mathrm{E}}$ and $\underline{\mathrm{V}}$.

Moreover, we can write, neglecting ohmic voltage drops: 


$$
\frac{\mathrm{E}}{\mathrm{L} \omega}=\mathrm{I}_{\mathrm{sc}}
$$

With $I_{\text {sc }}$, RMS value of the short-circuit current.

This allows us to express the maximal convertible power:

$$
\mathrm{P}_{\max }=3 \mathrm{VI}_{\mathrm{sc}}
$$

Note: The value of $I_{s c}$ is equal to the product of the shortcircuit current density of the section of a conductor. And this section, near the fill factor equal to the coil section divided by the number of conductors. This means that it is possible to increase the maximal convertible power by reducing the number of turns! To convert the maximal power, $\delta$ has a value of $90^{\circ}$. So we have:

$$
V^{2}+E^{2}=(L \omega I)^{2}
$$

We can express the RMS value of the current $\underline{I}$ by:

$$
I=I_{s c} \sqrt{1+\left(\frac{V}{E}\right)^{2}}
$$

As:

$$
\mathrm{E}=\mathrm{n} \phi \omega
$$

With n, number of turns of the coil and $\phi$ RMS value of the magnetic flux. Expression of I becomes:

$$
I=I_{s c} \sqrt{1+\left(\frac{V}{n \phi \omega}\right)^{2}}
$$

The electrical pulse to the base speed is given by:

$$
\omega_{\mathrm{b}}=\frac{\mathrm{V}}{\mathrm{n} \phi}
$$

Then:

$$
I=I_{s c} \sqrt{1+\left(\frac{\omega_{b}}{\omega}\right)^{2}}
$$

The $\cos \varphi$, at maximal converted power is:

$$
\cos \varphi=\frac{1}{\sqrt{1+\left(\frac{\omega_{\mathrm{b}}}{\omega}\right)^{2}}}
$$

The decrease in the number of turns leads, however, an increase in the RMS value of the current which results in a deterioration of the value of $\cos \varphi$. This change in the value of the number of turns must be dynamically, either by changing the configuration of the windings. The first solution is to have half windings in parallel or in serial and the second solution is to introduce a transformer between the voltage inverter and the synchronous machine. These are these solutions that we have developed and that we present later. These solutions are suitable for all synchronous machines associated to a voltage inverter.

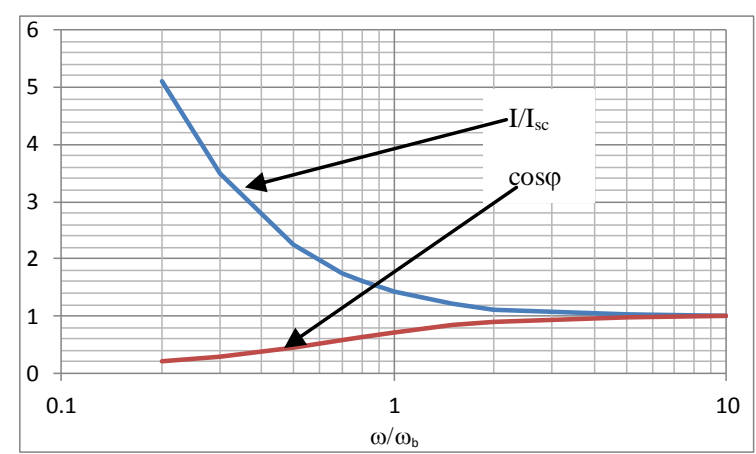

Fig.1: Evolution of the RMS value of the current with respect to the RMS value of the short circuit current and $\cos \varphi$ depending on the rotation speed, expressed through the relative electrical pulse (taken with respect to the electrical angular speed base).

In this article, we are particularly interested in the hybrid excitation flux switching synchronous machine (HEFSSM) for two reasons:

- This machine structure is potentially interesting for hybrid or electric vehicle applications;

- We have a laboratory prototype of this machine, in collaboration with the company Leroy somer Emerson, on which we have been able to implement the proposed solutions.

\section{2. HYBRID EXCITATION FLUX SWITCHING SYNCHRONOUS MACHINE}

\subsection{Presentation}

To present the operating principle, we rely on the description of a unit cell as shown in Fig. 2.

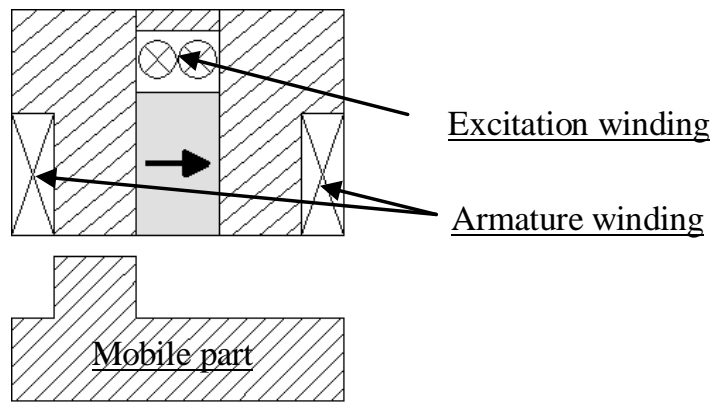

Fig.2: Presentation of a unit cell.

This particular structure uses the principle of flux switching, created by the movement of the mobile part. It retains the advantage of the simplicity of construction of the mobile part (rotor in a rotary machine), allowing high rotational speeds. It is noted that a concentration of flux can be easily achieved by acting on the shape of the magnets (shaded rectangular piece, Fig. 2, with an arrow indicating the direction of magnetization). In this type of electric machine, the armature coils and the exciting coils are located on the fixed part. This feature can be, in some applications, one advantage of electrically (simplicity of connectivity, no brush) and a benefit of the thermal point of view (the losses are removed by thermal conduction). 


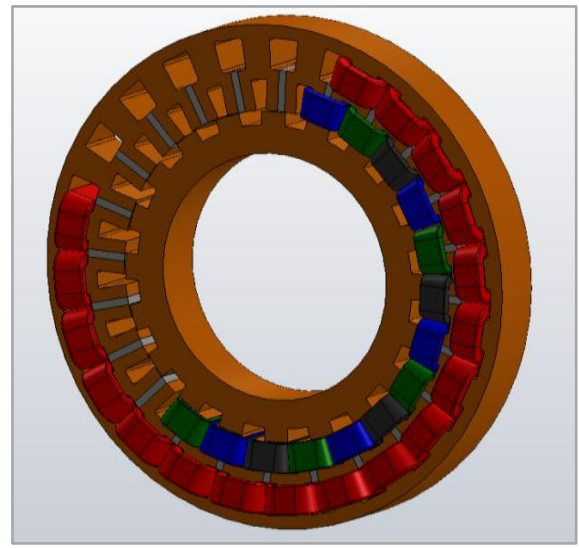

Fig.3a: Presentation of the HEFSSM prototype 24-20.

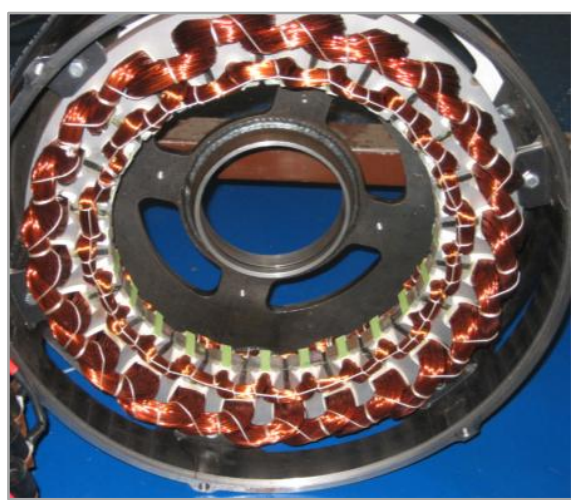

Fig.3b: Picture of stator of the HEFSSM prototype 24-20.

The prototype (see fig. 3a and $3 b$ ) by our industrial partner Leroy-Somer (Emerson group) is a three-phase synchronous machine containing 24 individual cells. Each armature phase is constituted by the series connection of 8 concentric coils. The rotor has $\mathrm{N}_{\mathrm{r}}$ teeth (here $\mathrm{N}_{\mathrm{r}}=20$ ). As a flux switching machine, the relationship between the frequency of mechanical rotation, denoted $\mathrm{F}$, and the electrical frequency, denoted $\mathrm{f}$, is given by the relation: $f=N_{r} F$.

\subsection{Principle of operation of the hybrid excitation}

As a flux switching machine, that is the position of the mobile part which requires the passage of flux in the armature coils. The excitation coil, supplied by a DC current, allows it, to modulate the amplitude of the flux, as shown in Fig. 4a to Fig. 4d.

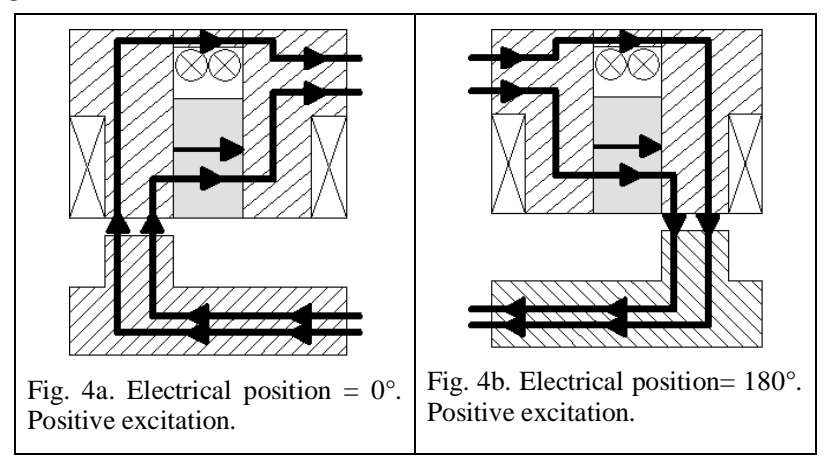

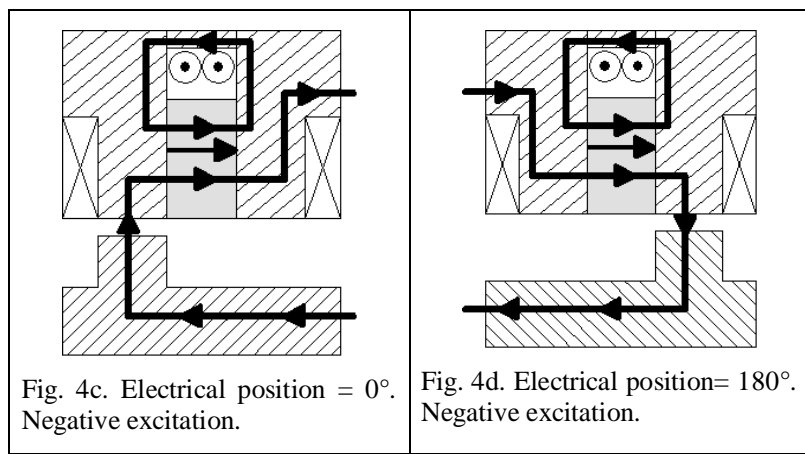

Fig. 5 presents the values of the amplitudes of the magnetic flux (maximum values), depending on the value of the DC excitation current density. This prototype was the subject of various studies, and we present the results for two types of permanent magnets $(\mathrm{PM}) \quad \mathrm{N}_{\mathrm{d}} \mathrm{F}_{\mathrm{e}} \mathrm{B} \quad\left(\mathrm{B}_{\mathrm{r}}=1.1 \mathrm{~T}\right)$ and ferrite $\left(B_{r}=0.4 T\right)$ and too without magnets.

For a positive excitation current, with $\mathrm{N}_{\mathrm{d}} \mathrm{F}_{\mathrm{e}} \mathrm{B}-\mathrm{PM}$, the flux variation is of the order of 1.7, for a maximum flux value of the order of $180 \mu \mathrm{Wb}$, whereas with ferrite-PM the flux variation is almost infinite (because the minimum flux is almost zero) for a value of maximum flux of about $150 \mu \mathrm{Wb}$. Without PM, the maximum flux is of the order of $100 \mu \mathrm{Wb}$.

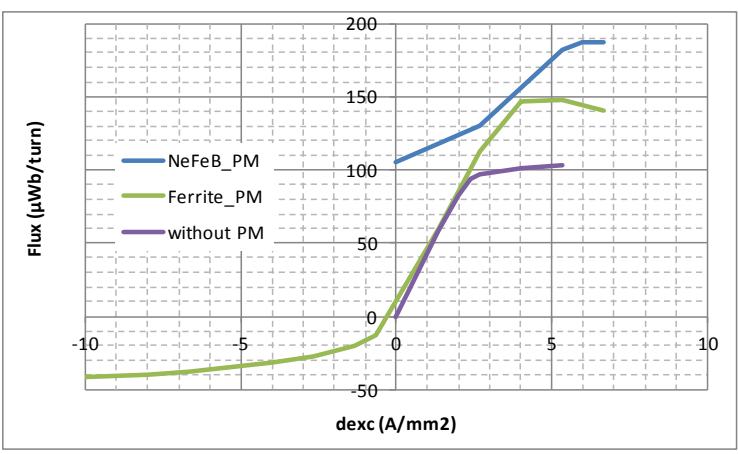

Fig.5: Amplitude of the flux depending on the density of the energizing current.

These numerical values are not indicated to conclude on the 'best' machine, but to illustrate the fact that beyond looking for performance, quality of PMs allows different functionality and a phase optimization is essential to make the most of this machine structure associated with a certain type of magnets.

For the remainder of the study, we use data on the machine with ferrite permanent magnets.

\section{MAXIMUM POWER OPERATION}

\subsection{Characteristics of the synchronous machine}

In Part 2 (elements of theory of voltage control) we showed that the intrinsic characteristics of the machine, namely the short-circuit current density determine the value of the maximum power that it is able to convert.

The RMS value of the short-circuit current for the machine with ferrite PM is presented in Fig. 6, depending on the excitation current. These measurements were made at a speed where the impedance of the inductance is greater than the value of the resistance. 
We can see that the RMS value of the short-circuit current depends on the value of the excitation current. This will be the setting for adjusting the power transfer. Saturation effects appear and are being investigated [5], but we can see that the saturation is fairly straightforward and we will place just at the elbow of saturation $\left(\mathrm{I}_{\mathrm{exc}}=4 \mathrm{~A}_{\mathrm{DC}}\right.$ and $\left.\mathrm{I}_{\mathrm{SC}}=3.8 \mathrm{~A}_{\mathrm{RMS}}\right)$.

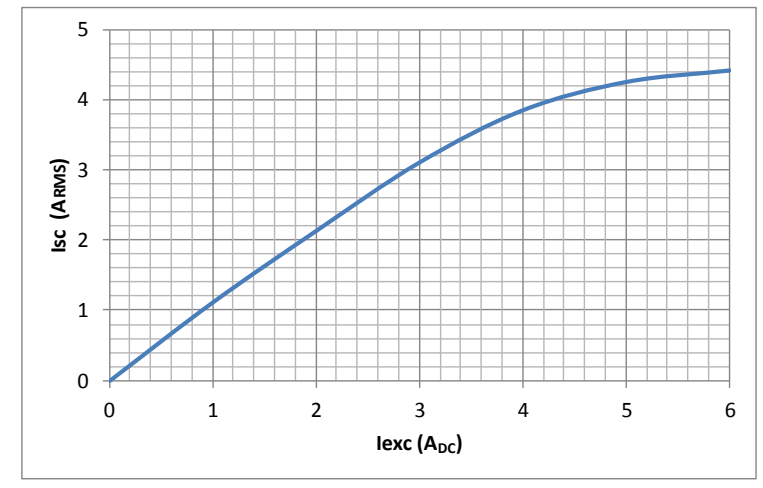

Fig.6: Experimental values of RMS short-circuit current as a function of excitation current.

\subsection{Experimental verification}

In order to experimentally validate the elements presented in the theory part 2, we realized the installation and the machine powered by means of a voltage inverter controlled in full wave voltage. Fig. 7 presents a measuring point where the main variables are presented for analyzing the energy conversion.

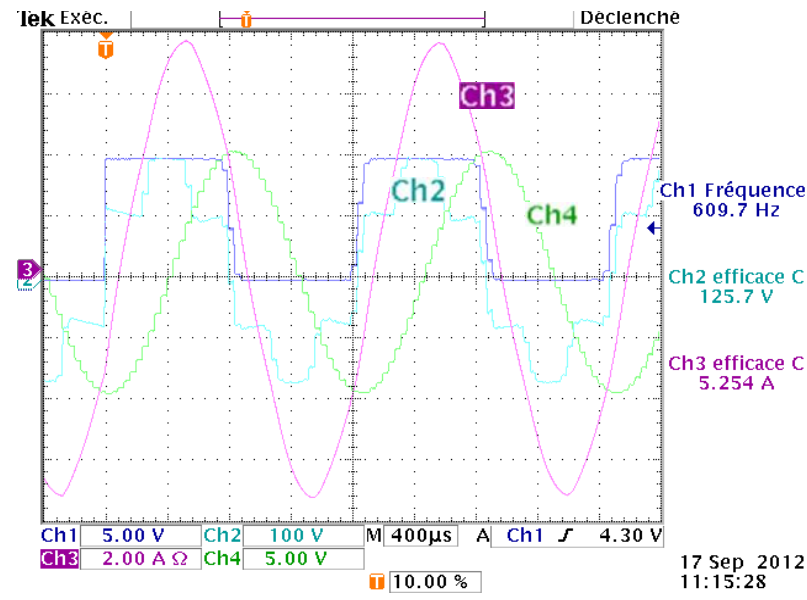

Fig.7: Operating point at maximal converted power at $1800 \mathrm{rpm}$.

On channel 1 (Ch1) is presented to the control signal. On channel $2(\mathrm{Ch} 2)$ is shown the phase to neutral voltage $(\underline{\mathrm{V}}$ image). The DC bus voltage is $300 \mathrm{~V}$. Note that the levels are $\pm 100 \mathrm{~V}\left(\mathrm{U}_{\mathrm{DC}} / 3\right)$ and $\pm 200 \mathrm{~V}\left(2 \mathrm{U}_{\mathrm{DC}} / 3\right)$. On channel $4(\mathrm{Ch} 4)$ is shown the image of the emf ( $E$ image). This signal is reconstructed using the information from the position sensor and the dspace ${ }^{\circledR} 1104$ tool. We notice that there is a phase shift of many $90^{\circ}$ between $\underline{\mathrm{V}}$ and $\mathrm{E}$ for this operating point where we got the maximal energy conversion. References [6] to [9] and [11] all deal with the energy efficiency of the chain of energy conversion $(\mathrm{VI}+\mathrm{EM})$.
Is presented in Fig. 8, changes in the RMS value of the current as a function of the rotational speed in the case of the maximal power conversion.

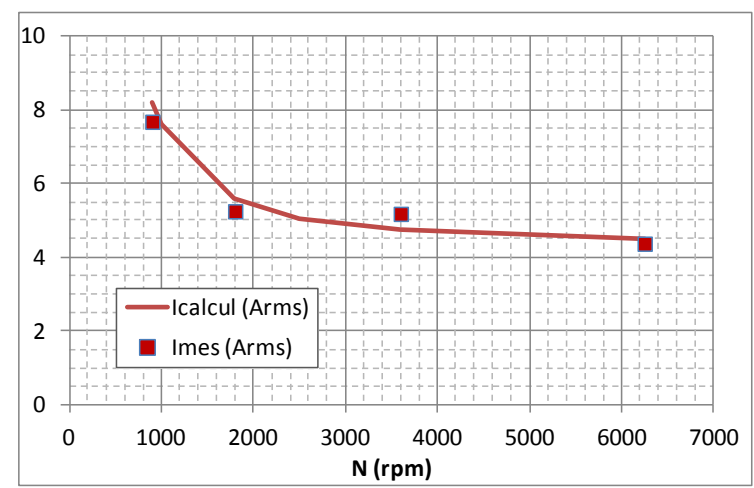

Fig.8: RMS current value for different rotational speeds, in the case where the power conversion is maximal.

The excitation current is maintained at a value of $4 \mathrm{~A}_{\mathrm{DC}}$ and we can see that according to the values shown in Fig. 6, the current value, for high rotational speeds, tends towards the value of the short-circuit current.

The maximal converted power, it remains substantially constant over the entire speed range (Cf. fig. 9).

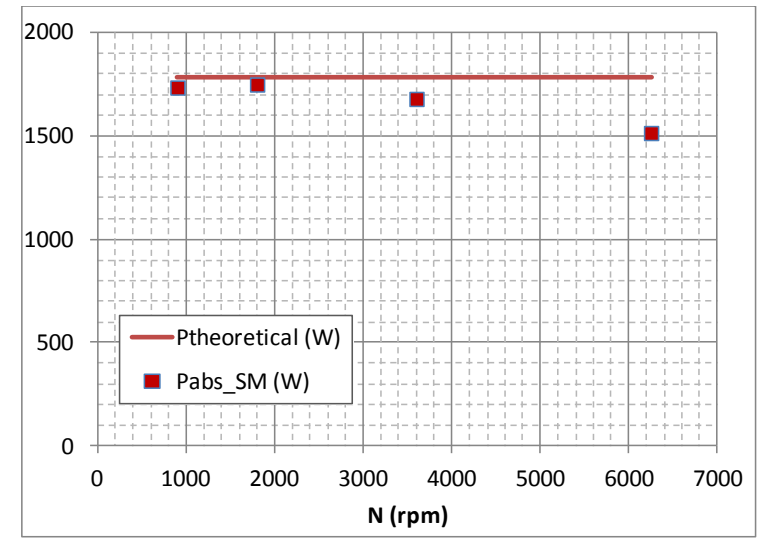

Fig.9: Maximal converted power depending on the speed of rotation.

The input power is measured at the DC bus, by measuring the average value of the current absorbed by the inverter. We assimilate the converted power by the EM with the input power at which we subtract only copper losses. Indeed, we do not have experimental device (mounting balance) to separate the iron losses and mechanical losses of the output power.

So the value of the power measured at DC bus due, we subtract the value of losses in the inverter and copper losses in the three phases of the machine. With the measurement of the effective value of the current absorbed by the machine and by assuming that the MOSFET inverter switches act as on-state resistance $\left(R_{D S O N}=500 \mathrm{~m} \Omega\right)$, we can deduce the value of the conduction losses of the inverter. We assume that switching losses are zero. To determine copper losses, we need the value of resistance $(1.8 \Omega)$ of a phase which has been measured at a winding temperature of $80^{\circ} \mathrm{C}$. It is that converted power by the SM which is shown in Figure 9.

For the operating point shown in Figure 7:

$\mathrm{P}_{\mathrm{DC}}=1940 \mathrm{~W} ; \mathrm{P}_{\mathrm{inv}}=40 \mathrm{~W} ; \mathrm{P}_{\mathrm{co}}=150 \mathrm{~W} ; \mathrm{P}_{\mathrm{SM}}=1750 \mathrm{~W}$ 
It should be noted that for a rotation speed of $6000 \mathrm{rpm}$, all losses and iron losses essentially entails heating occurs as a partial thermal demagnetization of PM (here ferrites) and thus, the ability to conversion of SM is diminished. This is one explanation is that the maximal convertible power by the SM decreases as the speed increases.

\section{SOLUTIONS TO INCREASE THE MAXIMAL CONVERTED POWER}

\subsection{Transformer between the inverter and the machine}

Place a three-phase transformer between the inverter voltage and the electric machine returns to change the RMS value of phase-to-neutral voltage. For our tests, we used a three-phase transformer 'traditionally' used on $50 \mathrm{~Hz}, 230$ $400 \mathrm{~V}, \mathrm{~S}=4 \mathrm{kVA}$. Figure 10 shows an operating point where maximal power is converted with the transformer between the inverter and the machine. These are the same values as those shown in Figure 7 The rotational speed of $2250 \mathrm{rpm}$ is such that the effective value of the current is substantially the same as for the test shown in Figure 7 (5.6A and 5.2A). It may be noted the increase in the RMS value of the phase to neutral voltage (190V instead of $125 \mathrm{~V})$.

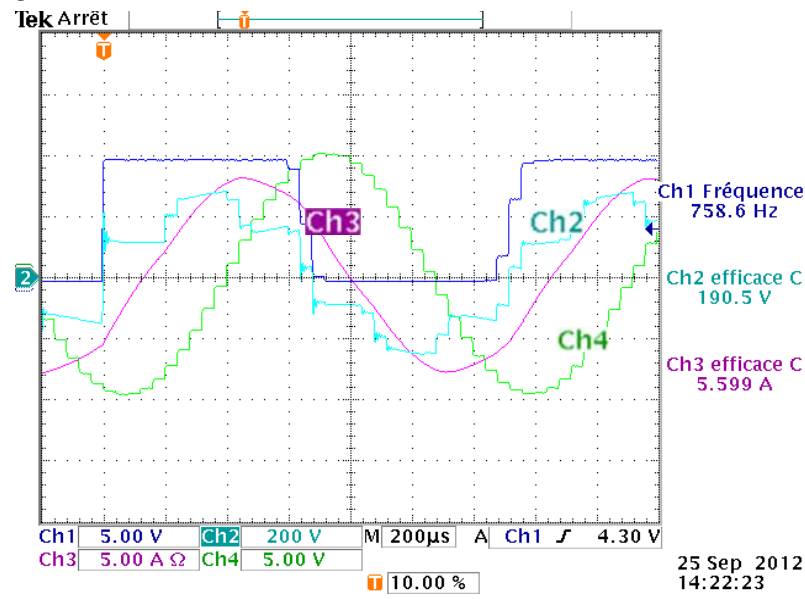

Fig.10: Operating point at maximal converted power at $2250 \mathrm{rpm}$.

For this operating point, the power measured at the DC bus $\mathrm{P}_{\mathrm{DC}}=2950 \mathrm{~W}$, the losses in the inverter, $\mathrm{P}_{\mathrm{inv}}=75 \mathrm{~W}$ and copper losses in the SM, $\mathrm{P}_{\mathrm{co}}=170 \mathrm{~W}$. Lacking the experimental device adequate we have not measured the losses in the transformer.

Through this process, we want to show that it is possible to increase the maximal convertible power by the set voltageinverter/synchronous-machine. We want to show, too, that this maximal convertible power has a direct impact on the maximal speed. Indeed, when the electrical machine is running in noload mode, that is to say without mechanical load, the power converted by the SM is converted into mechanical losses and iron losses. Given the fact that these mechanical losses and the iron losses increase with the rotational speed an increase in maximal convertible power leads to an increase of the maximal speed. Without transformer, the maximal speed is $6000 \mathrm{rpm}$, while with the transformer, it is $7500 \mathrm{rpm}$.

This solution requires the use of a new element inserted in energy conversion chain which results in a lower overall energy efficiency and an increase of the bulk element.
However, this solution can be considered when the EM is already built and the change of its parameters is not feasible. This solution may also be interesting in the case where the number of turns of the coils is too low and doesn't allow an easy realization.

\subsection{Paralleling half coils}

We have shown in Part 2 (elements of theory of voltage control) that the number of turns of the coils is important in determining the maximal convertible power. We propose a solution to dynamically change this number of turns. The solution is to combine, either in serial or in parallel each half coil constituting the armature phases. When operating at low speed, serial configuration is selected to maximize the power factor. For the 'high' speed of rotation, the parallel configuration is selected to increase the maximal convertible power while maintaining a 'good' power factor.

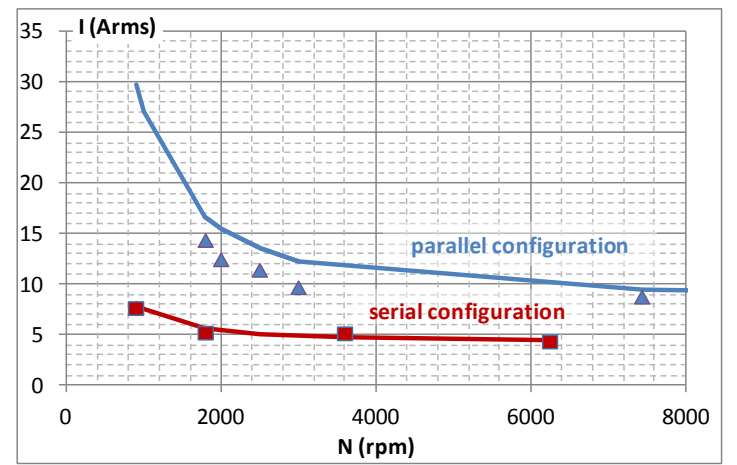

Fig.11: Evolution of the RMS value of the phase current according to the speed of rotation for the two configurations.

In Figure 11, we present the evolution of the RMS value of the current absorbed by the SM, which is the image of the inverse of the power factor. The measured values are indicated by squares or triangles either. The solid curves are the theoretical curves. It may be noted that at high speed the values tend to of the short-circuit values. We show that it is possible, by this method to multiply maximal convertible power by a factor 2. Figure 12 presents the experimental results and the theoretical calculations.

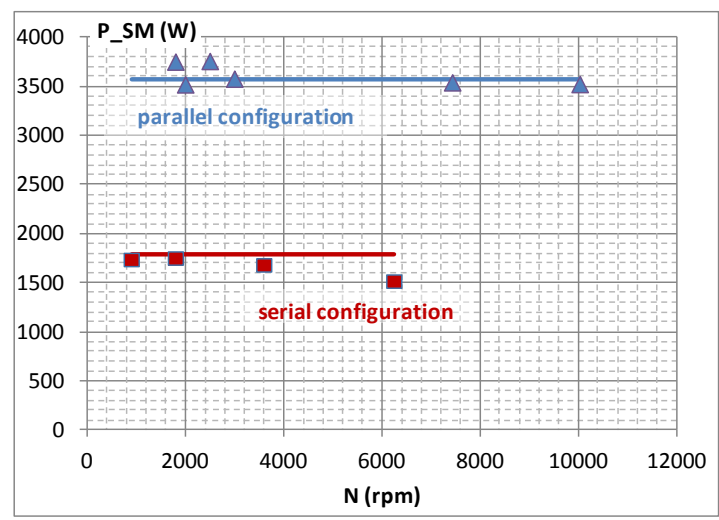

Fig.12: Evolution of the maximal converted power into a function of speed of rotation for both configurations.

The factor 2 of the maximal converted power is because with the parallel configuration, the RMS value of the short circuit current is also multiplied by a factor 2 . 
We present in Figure 13, the electrical parameters associated with energy conversion, namely the phase to neutral voltage (Ch2) and current (Ch3). It may be noted that the levels on the phase to neutral voltage are $\pm 100 \mathrm{~V}\left(\mathrm{U}_{\mathrm{DC}} / 3\right)$ and $\pm 200 \mathrm{~V}$ $\left(2 \mathrm{U}_{\mathrm{DC}} / 3\right)$. Again, we note that there has a $90^{\circ}$ phase difference between the phase to neutral voltage and the image of the emf (Ch4). Since this signal is determined using a digital signal processor (DSP) and reconstructed using a digital to analog converter (DAC), it appears levels which lasts equal to the sampling period (here, $40 \mu \mathrm{s} \Rightarrow \mathrm{f}_{\mathrm{s}}=25 \mathrm{kHz}$ ).

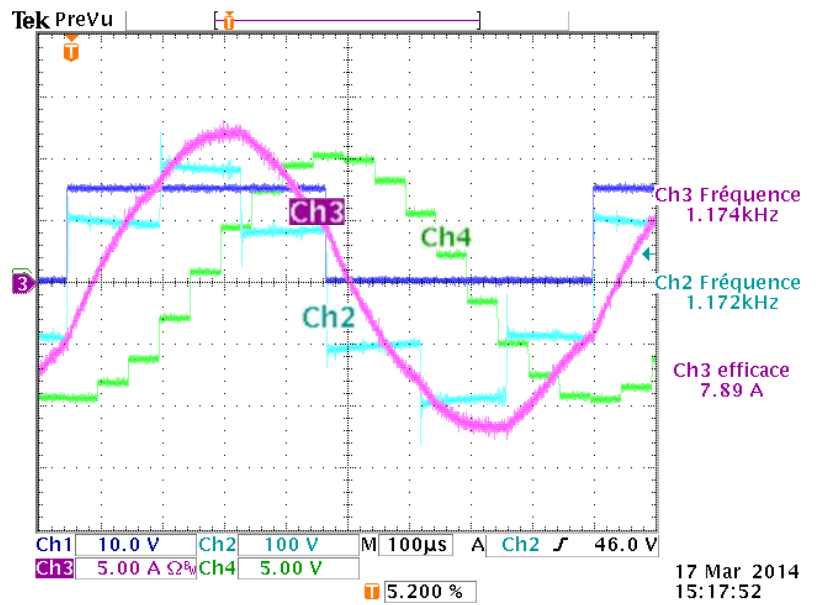

Fig.13: Operating point at maximal converted power, in parallel configuration at $3600 \mathrm{rpm}$.

The $1174 \mathrm{~Hz}$ frequency corresponds to a speed of 3516 rpm. For this operating point:

$$
\mathrm{P}_{\mathrm{DC}}=3700 \mathrm{~W} ; \mathrm{P}_{\text {inv }}=95 \mathrm{~W} ; \mathrm{P}_{\mathrm{co}}=85 \mathrm{~W} ; \mathrm{P}_{\mathrm{SM}}=3500 \mathrm{~W}
$$

It should be noted that copper losses are lower in this test $(85 \mathrm{~W})$ for the parallel configuration compared to the test shown in Figure 7 (150W in serial configuration) while the RMS current value is higher (7.9A vs $5.2 \mathrm{~A})$. This is because the resistance value of a phase is divided by a factor 4 (half-coil in parallel).

From a practical point of view, we were able to implement the parallel configuration using the fact that our prototype phase is carried out in its initial release, the series of eight concentric coils. So each armature phases is separated into two sets of four coils in series. So we can be put these, in series (serial configuration) or in parallel (parallel configuration).

\section{MAXimAl ROTATIONAL SPEED}

In section 5.2 (Paralleling half coils), we presented two configurations for the coils constituting the three phases of the machine. These phases, themselves being coupled in star connection. We looked experimentally the result of a delta connection of the three phases, on the maximal energy conversion. To do this we measured the RMS value of the shortcircuit current for the three cases with the same value of the excitation current $\left(4.5 \mathrm{~A}_{\mathrm{DC}}\right)$ :

1. Serial configuration and $\mathrm{Y}$ connection: $4.2 \mathrm{~A}_{\mathrm{RMS}}$

2. Parallel Configuration and $\mathrm{Y}$ connection: $7.8 \mathrm{~A}_{\mathrm{RMS}}$

3. Parallel Configuration and $\Delta$ connection: $13.2 \mathrm{~A}_{\mathrm{RMS}}$
We can see that between configurations 1 and 2, there is almost a factor 2 on the RMS values of currents and between configurations 2 and 3 , there is almost $1.7(\sqrt{3}=1.73)$.

The value of the short-circuit current measured for the parallel configuration and delta connection indicates that the EM is able to convert up a power in a ratio 1.7.

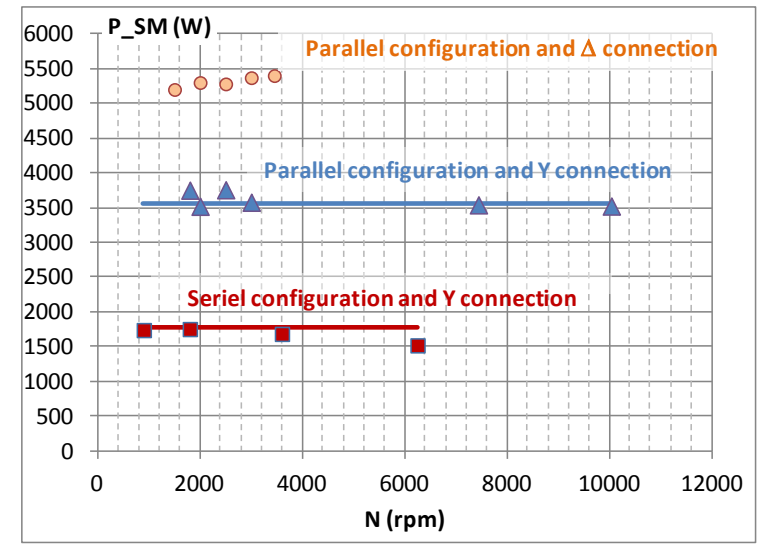

Fig.14: Maximal converted power for the three configurations.

We measured the maximal converted power by the EM for this configuration. But for these tests, we placed a wattmeter between the inverter and the EM. Power values shown in Figure 14 are for this configuration the power absorbed by the EM.

For the third configuration, the value of the maximal convertible power is about $5400 \mathrm{~W}$, whereas if we take the value for the second configuration $(3500 \mathrm{~W})$ and that multiplied by the ratio of the RMS values short circuit current (1.7) there are $5900 \mathrm{~W}$.

It should be noted that at these power levels, it appears voltage drops in devices (transformer, rectifier) lead to a dropvoltage on the DC bus (280V instead of $300 \mathrm{~V})$.

In Figure 15, we present the characteristic quantities of energy conversion. The current drawn by the EM is represented at $\mathrm{Ch} 3$ and the caliber of the vertical deviation is $20 \mathrm{~A} / \mathrm{div}$.

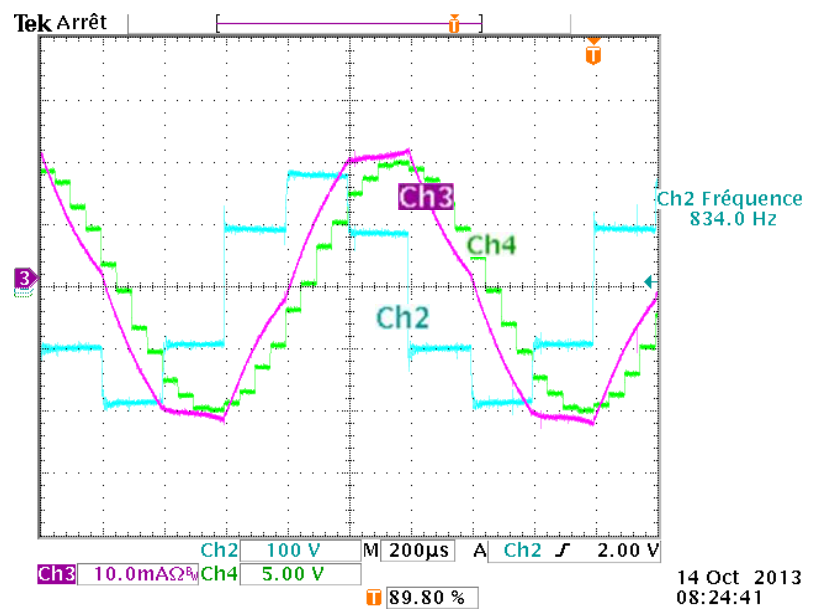

Fig.15: Operating point at maximal converted power, in parallel configuration and delta connection at $2500 \mathrm{rpm}$. 


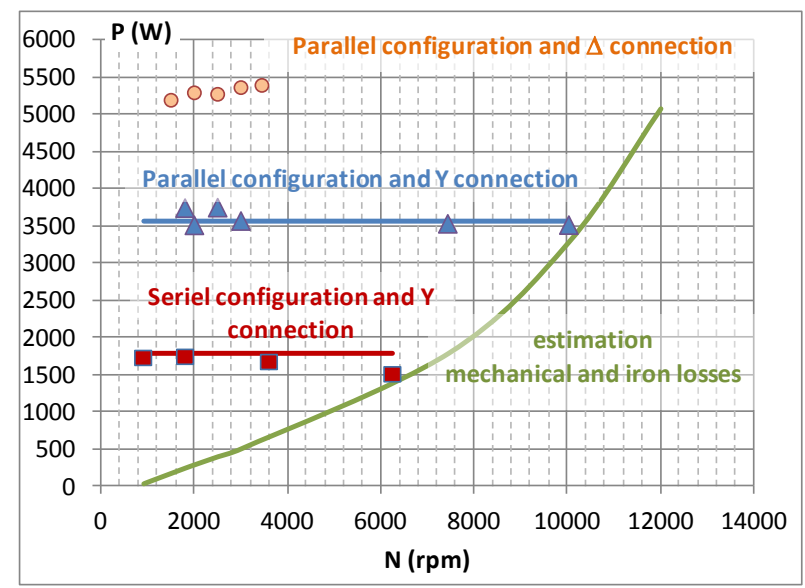

Fig.16: Maximal convertible power for the three configurations and an indication of the amount of mechanical losses and iron losses.

We completed the results shown in Figure 14, making appear an estimation of the sum of the mechanical and iron losses. This estimation was performed experimentally; the EM is in motor mode without mechanical load. A measure of the absorbed power by the EM in which the copper losses are deducted allows for an estimation of the sum of mechanical and iron losses. For the serial configuration the maximum speed, EM in no-load mode, is $6000 \mathrm{rpm}$ and for the parallel configuration, is $10,000 \mathrm{rpm}$. Both speeds are at the intersection between the curve of the estimated mechanical and iron losses and curve (almost horizontal line) of the maximal convertible power. For parallel configuration and delta connection, the intersection of both curves occurs at a speed slightly greater than $12,000 \mathrm{rpm}$. We managed to reach a speed of 13,935 rpm (see Fig. 17).

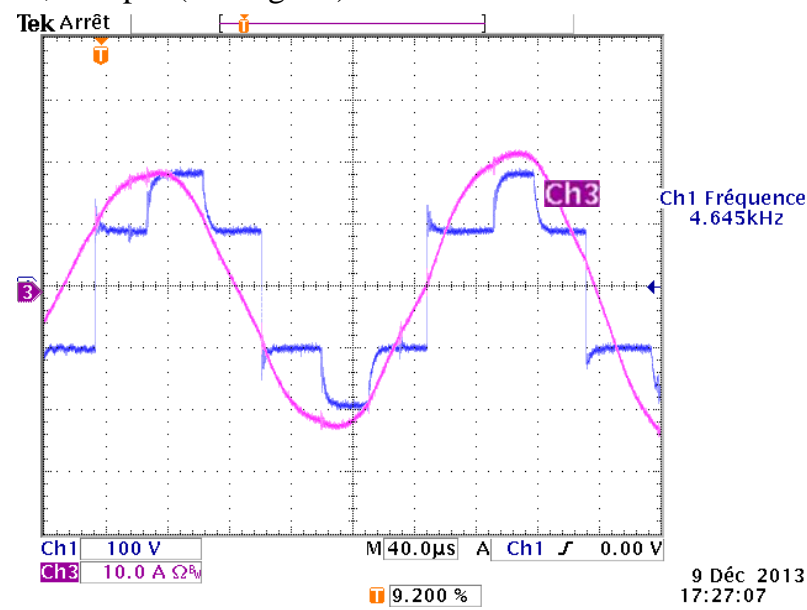

Fig.17: Operating point at maximal speed, in parallel configuration and delta connection at $13,935 \mathrm{rpm}$.

At this speed, the iron losses causes significant heating of ferrite permanent magnets which leads to a decrease in both the convertible power (via the reduction of the short-circuit current) and iron losses. The decrease in short-circuit current is proportional to the decrease in flux density of the magnet while the iron losses are proportional to the square of the value of the flux density, overheating led to greater reduction in iron losses associated with decreasing the maximal convertible power. Thus the maximal speed achieved is slightly greater than the 'theoretical' value.

\section{CONCLUSION}

In the variable speed applications, for example in hybrid or electric vehicles, it may be interesting to increase the convertible power by a voltage inverter associated with an electrical machine. This convertible power is limited. The maximal achievable value is dependent on the DC bus voltage value and on the short-circuit current of the electric machine, if it is a synchronous machine. In this paper, we presented two technical solutions to increase the maximal convertible power. The first solution is to insert a transformer between the inverter voltage and the electric machine (which can be either a synchronous machine that asynchronous machine). The second solution is to reconfigure the armature windings of the phases. For the implementation of this solution, the phases of the armature windings are divided in two similar parts. These coil halves beings may be connected in serial or in parallel. In the case of the parallel configuration, we show that it is possible to multiply in a factor two the maximal converted power.

\section{REFERENCES}

[1] E. Hoang, M. Lecrivain, M. Gabsi. ' A new structure of a switching flux synchronous poly-phased machine with hybrid excitation''.EPE-2007 Conference, Aalborg, September 2007.

[2] T.M Jahns. "Flux-weakening regime operation of an interior permanentmagnet synchronous motor drive", IEEE Transactions on Industry Applications, 1987, Issue 4, pp. 681-689.

[3] R. Schiferl, TA Lipo. "Power capability of salient pole permanent magnet synchronous motors in variable speed drive applications." IEEE Transactions on Industry Applications, 1987, vol 26, n ${ }^{\circ}$, pp. 115-123, January/february

[4] W.L. Soong, N. Ertugrul. "Field-weakening performance of interior permanent-magnet motors." Industry Applications, IEEE Transactions on, s.1. : IEEE, 2002, Issue 5, Vol. 38, pp. 1251-1258.

[5] M. van der Geest, H. Polinder, J.A. Ferreira, D.Zeilstra. "Design Considerations for Hybrid-Excited Flux-Switching Machines".

[6] K. Shingo, K. Kubo, T. Katsu, Y. Hata. "' Development of Electric Motors for the TOYOTA Hybrid Vehicle "PRIUS". Toyota motor corporation.

[7] B. Stumberger, A. Hamler, B. Hribernik. "Analysis of iron loss in interior permanent magnet synchronous motor over a wide-speed range of constant output power operation." Magnetics, IEEE Transactions on, : IEEE, 2000, Issue 4, Vol. 36, pp. 1846-1849.

[8] Yahia, H., Dhifaoui, R. et Multon, B., "Maximum power limits in the field-weakening mode of doubly-salient variable reluctance machines." 2002. IEEE. Vol. 2, pp. 783-788.

[9] Z.Q. Zhu, Y.S. Chen, D. Howe. "Online optimal flux-weakening contro of permanent-magnet brushless AC drives." IEEE Transactions on Industry Applications, s.l. : IEEE, 2002, Issue 6, Vol. 36, pp. 1661-1668.

[10] Z.Q. Zhu, Y.S. Chen, D. Howe. " Iron Loss in Permanent-Magnet Brushless AC Machines Under Maximum Torque Per Ampere and Flux Weakening Control." IEEE transactions on magnetics, vol.38, $\mathrm{n}^{\circ} .5$ september 2002, pp. 3285-3287

[11] L. Schwager, A. Tüysüz, C. Zwyssig, J. W. Kolar. "Modeling and Comparison of Machine and Converter Losses for PWM and PAM in High-Speed Drives."Conference ICEM-2012. 